\title{
GESTÃO DE BIBLIOTECAS PÚBLICAS HÍBRIDAS EM PROL DO DESENVOLVIMENTO DE COMUNIDADES
}

\author{
Management of hybrid public libraries in favour of the development of communities
}

\author{
Rafaela Carolina da Silva (1), Rosângela Formentini Caldas (1)
}

(1) Faculdade de Filosofia e Ciências - Universidade Estadual Paulista "Júlio de Mesquita Filho", Av, Hygino Muzzi Filho, 737 - Marpilia/SP, rafaelacarolinasilva@gmail.com, rcaldas@ marilia.unesp.br.

\begin{abstract}
Resumo
Ao considerar o ambiente de uma biblioteca pública como um organismo vivo, em constante mudança em direção ao desenvolvimento da sociedade, fala-se em espaços híbridos, onde tecnologias tradicionais e digitais se complementam. Nesse contexto, a aplicação das estratégias de gestão da informação em bibliotecas híbridas proporciona à sua estrutura organizacional o desenvolvimento de políticas públicas favoráveis ao desenvolvimento de comunidades, na medida em que contribui para o bom funcionamento da instituição. Nessa perspectiva, este capítulo propõe, por meio de estudos comparativos de casos múltiplos, estabelecer um elo entre os ambientes híbridos, a gestão informacional e o processo de desenvolvimento das comunidades através das bibliotecas públicas. Para tanto, trabalhou-se a aplicação da gestão da informação híbrida nas unidades de informação, a fim de visualizar se as mesmas prezavam pelo acesso e atendimento às necessidades gerais do seu público. Nesse contexto, o conceito de hibridez aplicado às bibliotecas permite o planejamento e a organização da informação de modo a comunicála com maior eficácia e eficiência. Dessa forma, o conceito de bibliotecas híbridas deve ser visto como uma das atividades potenciais das bibliotecas públicas no desenvolvimento de suas comunidades.
\end{abstract}

Palavras chave: Bibliotecas híbridas; Bibliotecas públicas; Gestão da informação; Desenvolvimento de comunidades.

\section{Introdução}

A sociedade em que vivemos demanda uma postura proativa na busca constante por informações para a geração de novos conhecimentos. No que diz respeito à interpretação e compreensão do mundo, a biblioteca é um ambiente que estimula nas pessoas nesse sentido para o exercício da cidadania.

No âmbito da biblioteca pública, o objeto a ser alcançado é diversificado, pois abrange a comunidade que a rodeia. Por isso, a instituição tem o compromisso social de possibilitar a construção de uma sociedade verdadeiramente democrática, na medida em que deve formar pessoas conscientes, críticas e reflexivas, levando-as ao exercício pleno da cidadania. Dessa maneira, como

\begin{abstract}
In considering the environment of a public library as a living organism, constantly changing towards the development of society, we talk about hybrid spaces, where traditional and digital technologies are complementary. In this context, the application of information management strategies in hybrid library provides to its organizational structures the development of public policies favorable to the development of communities, in so far as it contributes to the proper functioning of the institution. In this perspective, the problem of this research is linked to the potential that the hybrid libraries provide to society. From this perspective, this chapter proposes, through comparative studies of multiple cases, to establish a link between hybrid environments, informational management and the process of development of the communities through public libraries. Therefore, the implementation of the hybrid information management was applied in information units in order to see if they esteemed accessing and meeting the overall needs of the audience. In this context, the concept of hybridity applied to libraries allows the planning and organization of information in order to communicate it more effectively and efficiently. Thus, the concept of hybrid libraries must be seen as one of the potential activities of libraries in the development of their communities.
\end{abstract}

Keywords: Hybrid libraries; Public libraries; Information Management; Community development

destacam Barreto, Paradella e Assis (2008), tal instituição preocupa-se com o grau de imersão dos indivíduos nos processos decorrentes e geradores de informação e conhecimento.

Nesse contexto, ao se considerar o ambiente de uma biblioteca como um organismo vivo, em constante mutação e que se transforma em direção ao desenvolvimento da sociedade, fala-se em espaços híbridos, onde tecnologias tradicionais e digitais se complementam. $\mathrm{O}$ termo híbrido que, de acordo com Breaks (2002), tem suas origens na Teoria da Evolução de Darwin, designa-se como um novo modo de descrever tipos de serviços que buscam integrar fontes tradicionais e eletrônicas de informação. 
Consequentemente, a aplicação das estratégias de gestão da informação em bibliotecas híbridas proporciona à sua estrutura organizacional o desenvolvimento de políticas públicas favoráveis ao desenvolvimento de comunidades, na medida em que contribui para o bom funcionamento da instituição, potencializando os serviços institucionais e motivando os funcionários no contato com o público com quem trabalha. Dessa forma, com as tecnologias colaborativas de gerenciamento da informação disponíveis nas bibliotecas híbridas, além da convergência dos meios tradicionais com foco no espaço físico, os meios digitais também são mediados pelo ambiente eletrônico ou digital.

Logo, as unidades de informação, por meio de seus objetivos e metas, "localizam, entendem, disseminam e utilizam os conhecimentos gerados no trabalho para valorizar tanto a instituição como o aprendizado" (Caldas, 2012, p. 241). É nesse contexto que as habilidades humanas passam a ser desenvolvidas, juntamente com suas ferramentas de trabalho, para a elaboração de processos eficazes na disseminação da informação.

Como destacam Prakasan, Swarna e Kumar (2000), as bibliotecas passaram por quatro fases de desenvolvimento em relação às mudanças sociais: bibliotecas tradicionais, bibliotecas automatizadas, bibliotecas híbridas e, mais posteriormente, bibliotecas digitais. Portanto, a biblioteca híbrida é a ponte entre as bibliotecas tradicionais e digitais, utilizando fontes de informação em diferentes formatos e em localizações remotas ou locais, apresentadas de forma integrada.

O conceito de ambientes informacionais híbridos está diretamente entrelaçado com a argumentação de Garcez e Rados (2002, p. 46), de que os mesmos "extrapolem os limites da estratégia convencional, procurem visualizar o futuro e criem mecanismos para alcançar o propósito de atender às necessidades e expectativas de seus usuários". Sendo assim, cabe a elas estabelecer uma estrutura de melhoria continuada, na qual a qualidade dos produtos informacionais seja pensada e repensada de acordo com as ações a serem realizadas nas comunidades em que atuam.

A gestão da informação, nesse contexto, está relacionada ao fazer do profissional da informação de modo a conhecer quais os recursos e soluções adotar no processo de desenvolvimento de comunidades e disseminação da informação. Esse campo encontra-se respaldado pelo conjunto de valores que se destacam em determinada sociedade, em um dado espaço de tempo, para unificar materiais dos sistemas de informação em diferentes formatos, linguagem, e sumarizar a informação encontrada de tal modo que a informação buscada pelo usuário seja encontrada de maneira dinâmica, rápida e fácil.

O bibliotecário, antes um mero profissional tecnicista, passa a interagir com interfaces que estruturam a informação, propiciando determinar parâmetros para a geração de sentidos trazidos pelo uso dos recursos informacionais.

No ambiente interativo e incentivador das bibliotecas híbridas, os indivíduos passam a criar uma cultura de conhecimento, envolvendo o sistema de informação como um todo, construindo uma relação de multiculturalismo de dados, informações e conhecimentos de toda e qualquer natureza. $\mathrm{O}$ conceito de bibliotecas híbridas, então, deve estar presente na promoção da informação em bibliotecas públicas tanto no contexto analógico, de forma a pensar o ambiente físico interno e externo da biblioteca quanto no seu espaço digital.

Nessa perspectiva, deve-se compreender o novo sujeito social que se utiliza da biblioteca como sistemas de informação sociais, que deixam de ser meros receptores do conteúdo disponibilizado pela biblioteca e passam a reconstruir tais conteúdos de modo a gerarem novos conhecimentos. Dessa forma, estudou-se o potencial que as bibliotecas híbridas oferecem à sociedade, estabelecendo um elo entre ambientes híbridos, a gestão informacional e o processo de desenvolvimento das comunidades através das bibliotecas públicas, afinal, entende-se que a biblioteca pública tem um impacto direto na gestão de suas comunidades, proporcionando construção na cidadania, na ordem social, na tecnologia e na economia.

As palavras-chave que propiciaram a elaboração de estratégias de buscas bibliográficas sobre as temáticas abordadas foram: bibliotecas híbridas, bibliotecas públicas, gestão da informação, e desenvolvimento de comunidades. O segundo passo foi determinar os dados secundários externos sobre o tema de pesquisa, ou seja, coletar informações úteis já existentes, verificando a relevância dessas informações para a pesquisa e, consequentemente, elencar os dados primários a serem analisados.

Para fins de comparação entre as bibliotecas híbridas modelo, foram elencadas as seguintes características: capacitação dos funcionários com a visibilidade da mudança ao aspecto híbrido (bibliotecários híbridos); inclusão digital; ação conjunta entre a tecnologia, a estrutura física e o caráter humano; e a capacitação dos usuários para ambientes híbridos. A literatura especializada também delimitou alguns aspectos que foram estudados, a saber: políticas, estruturas organizacionais e tecnologias que apoiam e aprimoram o trabalho do bibliotecário junto às mudanças e demandas sociais.

Por fim, por meio do método comparativo, foram abordadas as características das bibliotecas híbridas internacionais, buscando detectar pontos em comum entre as mesmas e as bibliotecas híbridas brasileiras. 


\section{Ensino e aprendizagem: interação entre o homem e os diferentes meios tecnológicos}

As relações de ensino e aprendizagem partem da convivência dos seres humanos para com os diferentes contextos e meios tecnológicos. Essas vivências proporcionam diretrizes para que uma ideia possa ser processada mentalmente pelo indivíduo e, posteriormente, entendida de acordo com a sua experiência no assunto.

As necessidades de informação nascem e variam conforme as características dos indivíduos, as circunstâncias e o meio ambiente no qual estão envolvidos (Figueiredo, 1994). O acesso, por meio de políticas públicas, tecnologias e estruturas organizacionais, às estratégias de desenvolvimento de comunidades as quais as bibliotecas híbridas estão inseridas, é que tornam uma pessoa cidadã e, consequentemente, incluída socialmente. Nessa perspectiva, a construção da cidadania nos ambientes de informação, mais especificamente no Brasil, deve levar em conta: a identidade cidadã do bibliotecário; o seu poder de intervenção na sociedade; a identidade profissional do bibliotecário brasileiro; a autonomia de sua profissão dentro da sociedade brasileira; o que ele pensa como seus compromissos de classe; o que a sociedade civil pensa sobre os compromissos de classe do bibliotecário; o que os diversos povos brasileiros pensam sobre os compromissos que teriam os bibliotecários para com esses povos; a forma como os bibliotecários poderão conhecer os diversos povos brasileiros do ponto de vista de suas necessidades de construção de uma cidadania brasileira; e o sentido divergente e errático, não contraditório, com o qual o bibliotecário brasileiro constrói o seu discurso político em sociedade.

Nesse sentido, como enfatiza com Jorente (2012), os indivíduos formam esquemas mentais, baseados em linguagens e codificações. Esses quadros formam uma imagem mental que, juntamente com as demais linguagens convergentes, se transformam em um significado.

O processo de reconhecimento da informação se dá, então, em forma de espiral, ou seja, a partir de uma necessidade de informação, o indivíduo busca uma publicação apropriada para solucionar suas dúvidas e, conjuntamente com seu conhecimento prévio de mundo, gera um novo conhecimento. "O conhecimento supõe que o sujeito aprende o significado da informação, atribui-lhe um sentido necessitando da incorporação de um segmento significativo daquela." (Sacristán, 2002, p. 210).

Ao mesmo tempo em que há a geração desse reconhecimento, há também o compartilhamento do mesmo, seguindo, assim, em uma sequência espiral contínua. "Nesse contexto, uma formação profissional que se delineia como ideal é aquela voltada para a construção da cidadania consciente e ativa." (Castro, 2002, p. 189).
Em relação às Tecnologias de Informação e Comunicação (TIC), a percepção e geração de significados se dá, segundo Fauconnier (2001), de acordo com fusões conceituais. Para o autor, essa interação começou a ocorrer a partir da interação homem-mousecomputador (desktop).

Portanto, é a prática diária e o desejo de aprender que fará com que uma pessoa consiga ou não se relacionar de forma segura com as diferentes mídias e tecnologias. Nesse contexto, destacam-se três fusões relacionadas a interfaces computadorizadas:

- A percepção que o ser humano tem de objetos tridimensionais na tela de um computador (contando que a mesma é bidimensional). Logo, o sujeito passa a buscar um equilíbrio imagético, onde se possa enxergar uma demonstração tridimensional em um aparelho dimensional.

- O cursor do mouse se apresenta em forma de uma flecha vertical, que pode atuar tanto vertical, como horizontalmente. O cérebro, então, faz uma fusão conceitual, juntando um aparelho dimensional a um objeto tridimensional, que pode se locomover em diferentes direções.

- $\quad$ O mouse, ligado ao computador, faz com que o indivíduo faça movimentos diversificados enquanto navega no desktop. É uma convergência tátil, visual e sensorial que o homem dispõe para utilizar o dispositivo.

Fazendo um paralelo com os ambientes híbridos, é esse esforço diário que determinará a relação de alguém no entendimento das mesmas. $\mathrm{O}$ processo não é restrito à linguagem verbal, mas sim uma fusão conceitual de valores e linguagens.

O cérebro humano enquadra e liga pensamentos por meio de conhecimentos de rápida memorização (aqueles que não possuem longo período de armazenagem no cérebro, ou seja, a memória temporária) e de longa memorização (as informações processadas, entendidas e que passam, por longo período, armazenadas em nosso cérebro: a memória de longo prazo). Dessa forma, os espaços mentais são preenchidos de acordo com as necessidades de cada tipo de conhecimento.

O pensamento é fruto da percepção que, no ser humano, pode ser, racional, subjetiva e criativa. O observador de um mesmo objeto pode entendê-lo de diferentes formas a cada olhar, dependendo de seu ponto de vista.

A percepção humana é irregular e temporária. Nesse contexto, as TIC, em constante transformação, ligam-se ao pensamento humano na medida em que as inovações em seu âmbito variam suas percepções a cada dia.

A criatividade é capaz de fazer com que um conceito abstrato se torne coerente a cada percepção. A visão 
não estática dessas tecnologias e linguagens demanda, aos profissionais da informação, uma postura dinâmica em relação ao ensino-aprendizagem das TIC tanto pelo pessoal interno de uma unidade de informação, quanto para seus usuários.

Dessa forma, o uso de linguagens convergentes no processo de hibridização de um ambiente pressupõe um estudo diário das necessidades, desejos e diretrizes da biblioteca e do público dessa instituição, no que tange ao aprimoramento das técnicas pessoais de percepção. Sendo assim, as tecnologias analógicas e digitais convergem no tempo e no espaço, de acordo com sua forma e velocidade de disseminação da informação.

Dessa maneira, a obtenção de significados é obtida é obtida de acordo com a especificidade de cada sistema. Advindos de diferentes pensamentos, a percepção e a geração de conhecimento não são previsíveis, variando de indivíduo para indivíduo, de sociedade para sociedade, de unidade para unidade.

Logo, cabe aos profissionais da informação estudarem o contexto do local em que trabalham, para melhor se capacitarem e capacitarem seu público. Mudanças na forma de pensar são percebidas, ao passo que a atração ou não por determinado assunto ou tecnologia pode interferir na busca de seu aprendizado. Informações são recontextualizadas e reformuladas na medida em que um contexto passa a ser mais atrativo do que o outro.

É nessa perspectiva que a biblioteca híbrida se torna um lugar atrativo à percepção de quem a observa, treinando profissionais capacitados a lidar com as necessidades informacionais dos usuários com quem trabalha.

Os agentes da informação passam a moldar relações entre seus serviços oferecidos e a emergência de necessidades complexas em sistemas de informação. Há, assim, uma auto-organização de ensino por parte dos profissionais da informação, bem como uma autoorganização de aprendizagem por parte dos usuários de uma biblioteca.

Com a tecnologia computadorizada, ocorre uma mudança na forma como as informações são reunidas. As tecnologias, nesse sentido, são extensões dos homens (Mcluhan, 1969), pois é a partir da construção de conhecimentos feita pelo homem, que novas representações perceptivas surgirão. As TIC, então, estabelecem uma convergência de linguagens interativas, onde imagem, texto e som trabalham em um mesmo contexto.

A participação social, nesse sentido, é essencial para a difusão da inclusão digital, contando com o trabalho do bibliotecário, em conjunto com seu público, para contribuir para a construção de uma consciência coletiva de criação de conhecimentos perante as novas linguagens e mídias sociais.

\section{Bibliotecas públicas híbridas}

A biblioteca pública é uma célula viva, uma imagem muito forte do que a sociedade representa, e suas políticas refletem a missão da instituição perante a comunidade na qual está inserida. Trata-se, portanto, de "[...] um organismo que converge seus objetivos em favor do usuário, para suas necessidades e particularidades de informação" (Suaiden; Bernardino, p. 34-35, 2011) a fim de oferecer acesso à informação para todos, ou seja, democratizando a informação e formando cidadãos conscientes. No mesmo sentido, a biblioteca pública pode ser considerada um bem cultural, onde as informações são disseminadas de forma a facilitar o acesso dos usuários às informações produzidas em sociedade.

Na trajetória do desenvolvimento das bibliotecas híbridas (1) no Reino Unido, a mesma começou um tanto improvável. A abolição em 1992, da "divisão binária" entre as velhas universidades e os cursos politécnicos visava o impacto dessas novas bibliotecas na qualidade das pesquisas. Esse assunto foi base para o Joint Funding Consils' Libraries Review Group, que, em novembro de 1993, produziu o Follet Report, um relatório referido ao presidente da comissão, Prof. Brian Follet, no qual abrangia abordagens de sistemas e redes de infraestrutura para as bibliotecas do Reino Unido (International Federation Of Library Associations And Institutions, 2002).

A biblioteca híbrida, então, é a ponte entre as bibliotecas tradicionais e digitais, utilizando fontes de informação em diferentes formatos e em localizações remotas ou locais, apresentadas de forma integrada. Logo, os produtos e serviços oferecidos aos usuários de uma biblioteca híbrida devem ser integrados, proporcionando a flexibilização necessária para abranger a diversidade de usuários reais e potenciais da unidade.

A biblioteca pública, nesse cenário, passa a ser um local que permite o contato com outras pessoas, além do acesso à informação, "[...] permitindo o desenvolvimento de projetos criativos, culturais, empresariais e de meio ambiente, entre outros" (Rodríguez Santa María, 2013, p.11). É um lugar onde os indivíduos podem reunir seus próprios pensamentos com os de diferentes pessoas por meio da interação usuário-tecnologia.

Dessa maneira, as relações entre a sociedade e a organização informacional se fazem presentes de modo a promover, à comunidade que as cerca, oportunidades de se incluir informacionalmente. Por essa razão, o conceito de bibliotecas híbridas rompe parâmetros consolidados de ver e compreender, interferindo na disseminação e geração de conhecimentos. O exercício de "ver" passa a ser mais criativo, verificando-se "[...] mudanças significativas das formas de aquisição, organização, arquitetura e articulação da informação no 
exercício de um viver mais criativo na contemporaneidade" (Jorente, 2009, p. 2).

Neste cenário, as questões socioculturais que permeiam a contemporaneidade passam a ter novas configurações de integração dentro do caráter informacional e, portanto, ampliam-se trajetórias para novas atitudes, agora com um aspecto de comportamento cidadão e conscientização, que possibilitam que o indivíduo participe mais ativamente das questões ligadas à sua comunidade. Concomitantemente às bibliotecas tradicionais, que abrem espaços para o acesso à informação, uma biblioteca híbrida define parâmetros comportamentais/mentais que permitem uma maior interação cognitiva aos usuários e ao proceder dos profissionais da informação.

No ambiente de uma biblioteca híbrida colaborativa existe uma maior flexibilização nos produtos e serviços oferecidos (Pinfield et al., 1998), já que há uma estrutura organizacional a qual propõe uma multiplicidade de linguagens no fazer biblioteconômico que abrangem os espaços híbridos. A biblioteca híbrida deve ser um espaço cultural que propicie a promoção de diálogos, onde população e tecnologias se relacionem, de forma que as informações registradas no local passam a ganhar vida na medida em que são utilizadas.

Segundo Russel, Gardener e Miller (1999), os requisitos básicos de uma biblioteca híbrida são: providência de serviços para descoberta, localização, requisição, envio/entrega e utilização dos recursos; o fornecimento de serviços deve ser consistente tanto para recursos locais ou remotos, independentemente do tipo de seu suporte; a estrutura organizacional deve ser flexível, permitindo o desenvolvimento de novos sistemas quando necessário; os sistemas devem basear-se em normas internacionais, permitindo o aumento do volume e o tráfego de recursos.

Trata-se, portanto, do "balanço entre o impresso e o digital. Há uma coexistência de coleções em formato tradicional e digital e a que perpassam questões geográficas, por meio de uma rede de pesquisa e acesso providos dessas bibliotecas." (Oppenheim; Smithson, 1998, p. 99, tradução nossa). Destarte, há uma mediação entre os usuários e as ferramentas tecnológicas.

Logo, uma biblioteca híbrida combina, em seu ambiente, produtos eletrônicos e impressos, integrando funções das bibliotecas tradicionais e das digitais. No entanto, "Ao contrário de bibliotecas totalmente digitais, uma biblioteca híbrida aumenta as funções de uma biblioteca tradicional, em vez de substituí-las". (Prakasan; Swarna; Kumar, 2000, p. 293, tradução nossa).

Nessa perspectiva, o modelo híbrido é definido não só como a implementação de novos produtos e serviços digitais, como também serviços tradicionais baseados no impresso (Hodges; Lunau, 1999). Sendo assim, a biblioteca híbrida é designada para agregar diferentes fontes e tecnologias, "[...] refletindo o estado que hoje não é completamente digital, nem completamente impresso, utilizando tecnologias disponíveis para unir, em uma só biblioteca, o melhor dos dois mundos. (Garcez; Rados, 2002, p. 47).

É interessante, dessa forma, observar que um espaço híbrido se concentra na integração de serviços, e não na presença simultânea de suportes diversos. Refere-se ao crescimento de uma realidade específica para outra, e seus elementos se transformam de acordo com o desenvolvimento das suas comunidades.

\section{Gestão da informação híbrida e o desenvolvimento de comunidades}

A gestão da informação permite a visualização, o planejamento e a organização da informação de modo a disseminá-la com maior eficiência e eficácia. Assim, do mesmo modo que os ambientes híbridos contribuem para a convergência de suportes tradicionais e digitais, a gestão da informação planeja políticas e elabora planos, desenvolvendo estratégias de organização da informação (Von Krogh; Ichijo; Nonaka, 2001).

Logo, "À medida que os sistemas de informação se tornam mais globais e interconectados, a informação implícita é, muitas vezes, perdida". (Capurro; Hjorland, 2007, p. 194). É aqui, portanto, que se inserem os espaços informacionais híbridos como meios de inclusão da sociedade na comunicação da informação em unidades de informação.

O foco está no fato de ambientes híbridos possibilitarem a mediação dos conteúdos informacionais presentes no ambiente tradicional e digital das unidades de informação. Assim, a interação homem/máquina e biblioteca/sociedade é enfatizada, além de permitir uma maior facilidade na articulação do ambiente.

Levando em conta que a gestão da informação tem um papel fundamental nas unidades de informação, a gestão de tecnologias de inovação é algo que deve ocorrer para que as instituições não sejam vistas como um lugar obsoleto, mas sim como fontes disseminadoras da informação. Como proporcionadora de geração de conhecimento, a biblioteca pública deve atentar-se às necessidades e desejos de seus usuários, para que possa satisfazê-los informacionalmente, facilitando o acesso aos diferentes meios midiáticos disponíveis na sociedade.

Nesse contexto, os espaços híbridos conectam pessoas, informações e processos, formando uma rede de comunicação e troca de conhecimentos, aspectos propiciadores do desenvolvimento de comunidades. Os processos informacionais em bibliotecas devem, portanto, ser capazes de levantar informações acerca do seu contexto social (usuários e tecnologias), serem eficientes na disseminação da informação, planejar e propor respostas 
eficientes acerca das informações geradas e requeridas à instituição (Henrique \& Barbosa, 2009).

Torna-se necessário, nesse cenário, novas habilidades de gerenciamento e liderança para o planejamento das decisões relacionadas à organização e disseminação da informação a serem tomadas no local, já que "Possuir o melhor dos equipamentos de tecnologia da informação não é suficiente para prestar serviços de qualidade, mas também é essencial que os profissionais de biblioteca tenham em seus requisitos habilidades para lidar com tecnologia da informação de forma a poder controlar os seus próprios sistemas e [...] em sistemas externos e internos" (Prakasan et al., 2000, p. 294 tradução nossa).

Sendo assim, a aplicação estratégica da gestão da informação visa facilitar a interação entre o público e a instituição prestadora de serviços, evidenciando as características de interação e obtenção de informações acerca dos desejos e necessidades dos usuários. No âmbito da Ciência da Informação, o mesmo pode ser relacionado aos meios de disseminação da informação, sendo, nesse sentido, o usuário foco das atividades do profissional da informação, que deve sentir a biblioteca como um local agradável para o desenvolvimento de seus projetos.

\section{Resultados e Discussões}

O estudo mostrou que a biblioteca pública modelo no aspecto híbrido se encontra em Liverpool, no Reino Unido. A Abolição em 1992, da "divisão binária" entre as velhas universidades e os cursos politécnicos, que visavam o impacto dessas novas bibliotecas na qualidade das pesquisas foi um aspecto marcante para a trajetória do desenvolvimento das bibliotecas híbridas locais.

Esse assunto foi base para o Joint Funding Consils' Libraries Review Group, que, em novembro de 1993, produziu o Follet Report, um relatório referido ao presidente da comissão, Prof. Brian Follet, no qual abrangia abordagens de sistemas e redes de infraestrutura para as bibliotecas do Reino Unido (International Federation Of Library Associations And Institutions, 2002).

No Brasil, o Centro Interdisciplinar em Gestão Social (Ciags), da Universidade Federal da Bahia (UFBA) destaca o "desenvolvimento e aplicação de uma biblioteca híbrida, estabelecendo metodologias para que seja desenvolvido um conjunto de padrões para identificar, armazenar, disponibilizar e gerenciar as informações em diversas mídias" (Figueiredo et al., s.d.). Esse modelo também foi desejado pela Biblioteca Nacional de Brasília (BNB), que "desde o início, optou-se pelo modelo de "biblioteca híbrida", erroneamente anunciada pela imprensa como "exclusivamente digital" (Miranda et al. 2007, p. 21).

A Biblioteca de São Paulo - Carandiru é uma referência em bibliotecas híbridas brasileiras, pois faz parte do conjunto de iniciativas da Secretaria de Estado da Cultura para incentivar e promover o gosto pela leitura, que se dá tanto pelo livro tradicional como pelo digital. Além disso, em sua estrutura organizacional, os livros de papel convivem com as novas tecnologias, como $e$ readers, aparelhos que possibilitam a leitura de livros eletrônicos e outras mídias digitais.

O micro ambiente da biblioteca se contextualiza com a população e com o macro ambiente organizacional, o que faz com que a inclusão social seja prezada tanto pelos profissionais da informação quanto pela estrutura organizacional local. "O fascínio de adultos, jovens e crianças pelo mundo digital é uma das possibilidades de aproximação com a leitura. Por isso, não enxergamos os livros eletrônicos como rivais, mas sim como aliados na proposta de inclusão social por meio da leitura.” (Biblioteca de São Paulo, 2015).

Por fim, foi possível observar que há grande difusão do conceito de ambientes híbridos em países europeus e americanos, que estudam suas características desde a década de 1880. No entanto, estes estudos ainda são pioneiros no contexto brasileiro, possuindo, formalmente, apenas três bibliotecas públicas de cunho híbrido.

\section{Conclusões}

O mundo se transforma a cada segundo e, concomitantemente, influenciam as necessidades de informação dos indivíduos. Nesse sentido, este estudo prezou pelo desenvolvimento das comunidades que cercam cada contexto informacional, abrangendo, em sua estrutura física e formal, todos os tipos de usuários reais e potenciais da biblioteca, independentemente de raça, cor ou sexo.

É o papel da inclusão social reger tais ambientes, denominados híbridos, de modo que os mesmos promovam cidadãos reflexivos e partícipes em sociedade. As bibliotecas, assim, devem ir de encontro com as demandas sociais e culturais, a fim de não se perderem no tempo e/ou tornarem-se lugares desatualizados.

Para tanto, o estudo da convergência de linguagens e mídias recorre ao desenvolvimento de espaços híbridos, muito bem divulgados nos países europeus e americanos, mas pouco usado pelos brasileiros. Dessa forma, partindo do estudo das bibliotecas híbridas modelos em âmbito internacional, é possível adequar suas características à gestão das bibliotecas públicas brasileiras.

O foco está no fato de ambientes híbridos possibilitarem a mediação dos conteúdos informacionais presentes no ambiente tradicional e digital das unidades de informação. Assim, a interação homem/máquina e biblioteca/sociedade é enfatizada, além de permitir uma maior facilidade na articulação do ambiente e na escolha do conteúdo a ser pesquisado. 
Essa nova concepção oferece várias possibilidades na pesquisa, armazenagem, processamento, recuperação e disseminação da informação, de modo que o profissional bibliotecário possa melhor desempenhar tais processos, oferecendo produtos e serviços de maior qualidade aos seus usuários. Os usuários, nesse contexto, têm diferentes interesses informacionais.

Cabe ao bibliotecário navegar por sistemas de conhecimento e fontes de informação, assessorando seus usuários de acordo com seus problemas informacionais, gerindo sistemas de informação e transformando os dados e os fluxos de informação entre sistemas por meio da devida comunicação oral. Alia-se, portanto, os aspectos sociais aos culturais, a fim de educar seus usuários no uso da biblioteca e apoiar políticas de acesso à informação.

Isso requer da biblioteca uma busca constante pela eficácia da informação disponibilizada. Logo, o bibliotecário não pode mais ser visto como um guardador de documentos, pelo contrário, deve participar ativamente das questões políticas, sociais, educacionais e científicas que abrangem as bibliotecas.

\section{Notas}

(1) Oppenheim e Smithson (1999) destacam o termo, utilizado pela primeira vez em 1996, por Sutton, em seu capítulo publicado no livro "The roles of reference librarians, today and tomorrow".

\section{References}

Barreto, Angela Maria; Paradella, Maria Dulce; Assis, Sônia (2008). Bibliotecas públicas e telecentros: ambientes democráticos e alternativos para a inclusão social. // Ciência da Informação 37:1 (2008) 27-36, jan./abr. 2008. http://www.scielo.br/pdf/ci/v37n1/03.pdf (2015-09-25).

Biblioteca de São Paulo (2015). http://bibliotecadesaopaulo.org.br (2015-01-20).

Breaks, Michael (2002). Building the hybrid library: a review of UK activities. // Learned Publishing 15:2 (2002) 99-107. 2002.

Caldas, Rosângela Formentini (2013). Análise da integração da tecnologia em instituições de ensino superior através da gestão do conhecimento: Projeto Unintera. // Congresso Internacional TIC e Educação. Lisboa, Instituto de Educação da Faculdade de Lisboa, 237-251. http://ticeduca.ie.ul.pt/atas/pdf/74.pdf (2014-0910).

Capurro, Rafael; Hjorland, Birger (2007). O conceito de informação. // Perspectivas em Ciência da Informação 12:1 (2007) 148-207, jan./abr. 2007. http://portaldeperiodicos.eci.ufmg.br/index.php/pci/article/viewF ile/54/47 (2015-05-18)

Castro, César Augusto (2002). Ciência da informação e biblioteconomia: Múltiplos discursos. EDUFMA, São Luís, 2002.

Fauconnier, Gilles (2001). Mental spaces: Aspects of meaning construction in natural language. Cambridge University Press, New York, 2001. ww.ifi.unizh.ch/ailab/people/lunga/onferences/EDEC2/inveted/F auconnierGilles.pdf (2015-12-03).
Figueiredo, Messias B.; Fischer, Fernando. Silva, Suede M. Passos; Schommer, Paula. Biblioteca híbrida especializada em gestão social: Projeto piloto.

Figueiredo, N. M. de (1994). Informação como ferramenta para o desenvolvimento. // Tópicos modernos em ciência da informação. Lorena: Centro Cultural Teresa D'Avila, 1994, 77-102.

Garcez, Eliane Maria Stuart; Rados; Gregório J. Varvakis (2002). Biblioteca híbrida: Um novo enfoque no suporte à educação a distância. // Ciência da Informação 31:2 (2002) 44-51. http://www.scielo.br/pdf/ci/v31n2/12907.pdf (2015-05-17).

Henrique, Luiz Cláudio Junqueira; Barbosa, Ricarido Rodrigues. (2009). Busca da informação em marketing: A perspectiva da ciência da informação. // Revista de Administração de Empresas 49:2 (2009). http://www.scielo.br/scielo.php?script=sci_arttext\&pid=S003475902009000200008 (2015-09-11).

Hodges, Doug; Lunau, Carrol D. (2015). The National Library of Canada's digital libraries initiave. // Library Hi Tech 17:2 (2015) 152-164, jan. 2015. http://www.emeraldinsight.com/doi/pdfplus/10.1108/073788399 10275669 (2015-01-19).

International Federation of Library Associations and Institutions (2002). Libraries in the information society. https://books.google.com.br/books?id=WQgAAAAQBAJ\&printsec $=$ frontcover\&hl $=$ pt $\mathrm{BR \#} \mathrm{v}=$ onepage \&q\&f$=$ false $(2015-04-10)$.

Krogh, George Von; Ichijo, K.; Nonaka, Ikujiro (2001). Facilitando a criação de conhecimento: Reinventando a empresa com o poder da inovação contínua. Campus, Rio de Janeiro, 2001.

Mcluhan, Marshall (1969). Os meios de comunicação: Como extensões do homem. Cultrix, São Paulo, 1969.

Miranda, Antonio.; Leite, Cecília.; Suaiden, Emir (2008). A biblioteca híbrida na estratégia da inclusão digital na Biblioteca Nacional de Brasília. // Inclusão Social 3:1 (2008) 17-23. http://revista.ibict.br/inclusao/index.php/inclusao/article/viewFil e/116/112 (2015-04-10).

Jorente, Maria José Vicentini (2012). Ciência da informação: Mídias e convergência de linguagens na Web. Cultura Acadêmica, São Paulo, 2012.

Jorente, Maria José Vicentini (2009). Tecnologias, mídias, criação e hipertextualidade na transformação da informação em conhecimento interativo. Faculdade de Filosofia e Ciências, Universidade Estadual Paulista, Marília, 2009.

Oppenheim, Charles.; Smithson, Daniel (1998). What is the hybrid library? // Journal of Information Science, 25:2 (1998) 97-112. http://jis.sagepub.com/content/25/2/97.full.pdf+html (2015-0117).

Pinfield, Stephen; Russell, Rosemary; Eaton, Jonathan; Wissenburg, A.; Edwards, Catherine; Wynne, Peter (1998). Realizing the hybrid library. // D-lib Magazine, D-lib Alliance 5:10 (1998) 1-18. http://cdigital.uv.mx/bitstream/123456789/6565/1/baucis\%2000 83.pdf (2015-01-18)

Prakasan, E. R.; Swarna, T.; Kumar, Vijai (2000). Human resource development in hybrid libraries. // National Convention on Library and Information Networking. Chennai, Madtras, 292-299. http://eprints.rclis.org/5864/1/pdf.pdf (2015-01-18).

Rodrígues Santa María, Gloria María (2013). Bibliotecas vivas: As bibliotecas públicas que queremos. Secretaria da Cultura do Estado de São Paulo, São Paulo, 2013. http://bibliotecadesaopaulo.org.br/wpcontent/uploads/2013/05/Notas6_web.pdf (2015-01-17) 
Russel, Rosemary; Gardener, Tracy; Miller, Paul (1999). Hybrid information environments: Overview and requirements. http://www.ukoln.ac.uk/dlis/models/requirements/overview/ (2015-01-20).

Sacristán, J. Gimeno (2002). Educar e conviver na sociedade global. Artmed, Porto Alegre, 2002.

Suaiden, Jose Emir; Bernardino, Maria Cleide Rodrigues (2011). // Perspectivas em Ciência da Informação 16:4 (2011) 29-41, out./dez. 2011.

http://portaldeperiodicos.eci.ufmg.br/index.php/pci/article/view/ 1257/970 (2015-01-19).
Copyright: () 2016 Silva and Caldas. This is an openaccess article distributed under the terms of the Creative Commons CC Attribution-ShareAlike (CC BYSA), which permits use, distribution, and reproduction in any medium, under the identical terms, and provided the original author and source are credited.

Received: 2016-05-20. Accepted: 2016-05-20 